\title{
5. Council Working Groups: communities, hierarchies and the management of contestation
}

\author{
August Danielson
}

\section{THE ROLE OF THE COUNCIL WORKING GROUPS}

While standing in Schuman Square at the heart of the European quarter in Brussels, you can hardly miss the hundreds of officials walking in and out of the Justus Lipsius building, the headquarters of the Council of the European Union (EU). Many of the officials who enter the building are likely member state representatives to one of the 150 preparatory bodies to the Council, also known as the Council Working Groups (CWGs). These representatives play a significant, although often understated, role in the EU decision-making process. They prepare the decisions and filter the discussions that take place at a higher level, ensuring that the ministers of the Council only negotiate issues that the preparatory bodies were unable to find consensus on. In other words, the CWGs are the core of the EU decision-making machinery (Huhe et al., 2018). Despite this, we still know relatively little about the individuals who make up the CWGs, much less the working methods, practices and norms that structure their everyday work. In addition, few studies have aimed to understand how the position of the CWGs in the decision-making hierarchy impacts their practices and group identities.

This chapter aims to fill two knowledge gaps with respect to the CWGs. First, by focusing on the CWGs that specifically prepare and produce EU foreign and security policy, this chapter aims to describe the practices and processes of socialization that exist in the communities of practice that have sprung out of these contexts. Second, by comparing indicators on cooperation and negotiation patterns in a lower-level working group with a higher-level working group, as well as relating these differences to the currently existing practices in the two groups, this chapter aims to probe the potential effect of a CWG's hierarchical position on the development of its group identities and 
practices. This, in turn, will allow us to judge whether larger comparative studies on this potential effect are warranted.

Given the central role of the Council in the EU decision-making process in general, CWGs have a significant impact on the EU's policy output. This role is further augmented for the CWGs that prepare the Common Foreign and Security Policy (CFSP), as the Council does not need to coordinate with the European Parliament to take decisions on foreign and security policy, which is otherwise the case with the community method used in most other policy areas. Instead, CFSP decision-making follows the intergovernmental method. That is, with very few exceptions, member states must unanimously agree on a position in order for it to be taken. The CFSP CWGs should therefore be regarded as having a relatively larger influence in the policy-making process than the CWGs that prepare the decisions for other council configurations. This chapter focuses on two cases of CFSP CWGs: the Working Party on Eastern Europe and Central Asia (COEST) and the Politico-Military Group (PMG).

Unlike CWGs that prepare issues for policy areas other than foreign affairs, the CFSP CWGs meet very frequently. A recent study found that more than 35 per cent of all CWG meetings between 1995 and 2014 focused on foreign affairs (one of 17 policy areas), indicating that member states place relatively high political attention on foreign affairs issues (Häge, 2016). On the whole, the CFSP CWGs should be regarded as being remarkably efficient at doing their job. Previous studies have found that up to 90 per cent of Council decisions are agreed on before they reach the Council: roughly 70 per cent at the working group level and between 15 and 20 per cent in the Committee of Permanent Representatives (Coreper) (Duke and Vanhoonacker, 2006, p. 169; Hayes-Renshaw and Wallace, 2006). ${ }^{1}$

Beyond the efficiency of CFSP CWGs, previous research has also emphasized the informal norms and practices that characterize the inner workings of the CWGs. For example, Juncos and Pomorska highlight the coordination reflex (a process of consultation and information-sharing before a decision is taken), the consensus-building practice (avoiding isolating a single member state), and a joint will to make the CFSP work, as the main norms that structure the negotiations between member state representatives in CWGs (Juncos and Pomorska, 2006, 2011). Similarly, Duke and Vanhoonacker (2006, p. 179)

1 In the case of the CFSP CWGs, other estimates place the involvement of the Foreign Affairs Council (FAC) much higher. Juncos and Pomorska (2011, p. 1102) found that roughly 40 per cent of all decisions taken by the FAC were discussed by the foreign ministers. However, this number is arguably a bit misleading, as simply because an issue is discussed as a so-called 'B point' at an FAC meeting does not mean that the wording of a Council Conclusion has not already been agreed in a lower-level working group. 
find that an 'increasingly dense pattern of rules and procedures' has developed within the CFSP administrative bodies, including the CWGs, which has led to the development of a common language and an increasing influence in the agenda-shaping, decision-shaping and implementation phases of the CFSP policy cycle.

These findings echo those of Lewis's studies on Coreper (Lewis, 2000, 2003, 2005). Lewis found that a 'distinct style of making decisions has evolved' in Coreper, comprised of five main features: diffuse reciprocity, thick trust, mutual responsiveness, a consensus-reflex, and a culture of compromise (Lewis, 2000, p. 261). ${ }^{2}$ In other words, it is not obvious what sets the lower-ranking CWGs apart from the higher-ranking CFSP committees, such as the Political and Security Committee (PSC) and Coreper. Both sets of committees have similar instructions - that is, to find consensus - and their norms and rules described in the literature are more or less identical.

So far, the literature on CFSP administrative bodies has made few systematic comparisons between the different groups, ${ }^{3}$ which has prevented judgements about the effect of a committee's position in the decision-making hierarchy on the development of the specific practices and socialization processes that exist within that committee. Therefore, this chapter specifies how the lower-ranking CFSP CWGs differ from one another, as well as how the lower-ranking CFSP CWGs differ from higher-ranking preparatory bodies, in this case, the PSC. These comparisons should be regarded as the main theoretical contribution of the chapter, as we know relatively little of the effect that a group's hierarchical position, as well as group-level variation in terms of their members' professional backgrounds and experiences, have on the development of practices within a community of practice. In addition, by looking at how such mechanisms intertwine, we may also come to a greater understanding of how and why communities of practice differ in terms of the ways in which they manage contestation. In this sense, the chapter primarily contributes to the overarching aim of this volume of identifying and understanding variation within the CFSP architecture regarding how micro-level contestation management and social learning works in practice.

The rest of the chapter is structured as follows. First, the CFSP CWGs are situated in the CFSP decision-making hierarchy, mainly focusing on their relations to other CFSP bodies. Second, the two main case studies for this chapter, COEST and the PMG, are described. Third, two comparative analyses are made between the PMG and the PSC, and between the PMG and COEST. The first analysis is primarily based on quantitative data from the Negotiations in

For an opposing view on the 'consensus norm' in Coreper, see Naurin (2015).

For one exception, see Chelotti (2016). 
the Council of the European Union (NCEU) dataset, and the second analysis is based on interview data from 2020 (see Appendix 1 for a detailed description of both data sources). These two analyses allow us to determine the currently existing practices within COEST and the PMG (including practices regarding contestation management), how these practices are learned, and how the existing practices and group identities vary between the lower-ranking and higher-ranking working groups.

\section{THE POSITION OF THE CWGS IN THE CFSP DECISION-MAKING HIERARCHY}

The main purpose of the CWGs can be summed up as striving to find as much common ground as possible between member states, to minimize the number of issues or dossiers that are sent to a higher level in the decision-making hierarchy. For the CFSP, the hierarchy can be divided into four levels (from lowest to highest): (1) roughly 30 thematic and geographic working groups; ${ }^{4}$ (2) the PSC; (3) Coreper II; and (4) the Foreign Affairs Council (FAC) in other words, the formation of the Council of the European Union that deals with foreign affairs. The FAC is constituted by the foreign ministers of each member state and convenes once per month in Brussels to take decisions related to the CFSP. In addition, although not part of the ordinary CFSP decision-making process as most decisions are taken by the FAC, the European Council (EUCO) essentially acts as a fifth level above the FAC. The EUCO has the responsibility to set the EU's 'general political direction', including foreign affairs, and has recently become an increasingly active 'top player' in the CFSP hierarchy (Maurer and Wright, 2020, p. 10). The CFSP decision-making hierarchy is illustrated in Figure 5.1

This CFSP decision-making process usually begins with the rotating Council presidency, with the support of the General Secretariat, delegating an issue to one of the roughly 30 currently existing CFSP working groups, each managing a specific foreign affairs issue or geographic area. The working group then works to find consensus on the issue(s) or file(s) that it has been delegated by the presidency and for which it is responsible. When it is unable to find consensus, these issues or files are usually sent to the PSC, where further negotiations are conducted. Since the PSC has the responsibility to coordinate all issues that fall within the CFSP, this gives the PSC ambassadors greater political weight, in the sense that they are able to make compromises

4 For a complete list of the current CFSP CWGs, see List of Council Preparatory Bodies (C.1-C-39), Council document no. 5020/21. Available at: https://data.consilium .europa.eu/doc/document/ST-5020-2021-INIT/en/pdf. 


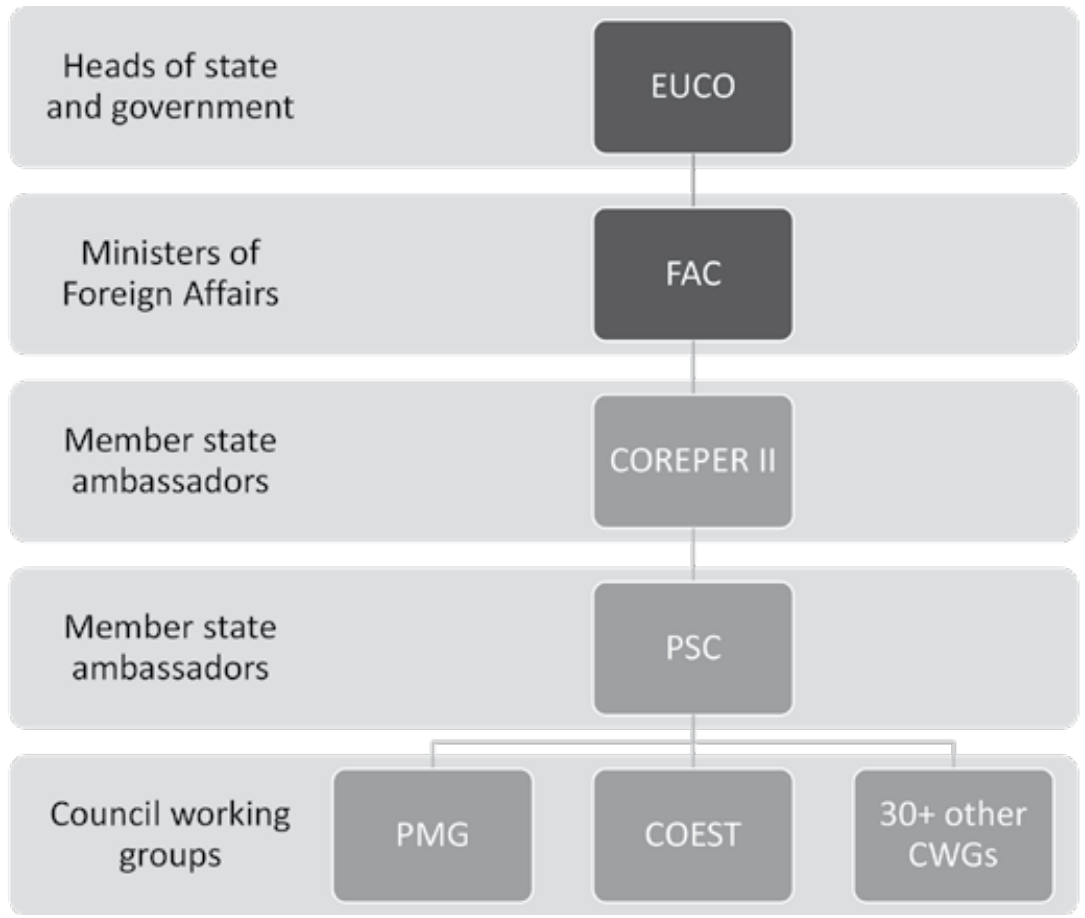

Figure 5.1 The CFSP decision-making hierarchy (preparatory bodies in light grey)

that their lower-level counterparts do not have the authority to make; they also bear a larger share of the burden to actually find consensus and not just discuss the issue:

There is more political pressure about their [PSC ambassadors'] position, and the pressure from the capital is higher - the stakes are higher. The people are more advanced in their career and maybe more ... aware about that they need to be efficient, otherwise there will also be an effect on their career. (COEST 8)

However, if consensus cannot be found among the PSC ambassadors, the issue or file is sent to Coreper, the highest-ranking CWG. Given the large workload of Coreper, the group is divided into two configurations. Coreper II, consisting of the member states' ambassadors and permanent representatives to the EU, is responsible for issues related to general affairs, foreign affairs, economic and financial affairs, as well as justice and home affairs. Therefore, Coreper II is the final preparatory body for decisions taken in the council formations for these four issue areas. Coreper I, consisting of the member states' deputy 
permanent representatives, is responsible for preparing the issues for all other Council formations. ${ }^{5}$

Given the fact that Coreper II deals not only with foreign affairs but also economic affairs, the committee is charged with discussing and preparing issues across many policy areas, unlike the PSC, which only has the authority to prepare issues related to foreign affairs. This also means that some issues discussed in geographic CFSP CWGs are sent to Coreper II and therefore automatically bypass the PSC if they are unable to find consensus. For example, one of the member state representatives to COEST noted that recent discussions on nuclear energy in Belarus fell outside the remit of the PSC as energy policy is not part of the CFSP (COEST 3).

In cases where neither the PSC nor Coreper II can find consensus, the draft Council Conclusion (or whichever text that is being negotiated) is either sent to the FAC as a discussion point or tabled. As mentioned, in some cases consensus can be found among the ministers when they meet in the FAC, but these situations are quite rare. In interviews with a significant number of PSC ambassadors, Maurer and Wright found that the FAC has been increasingly sidelined due to the heads of state in the EUCO taking on a much larger role in shaping EU foreign policy, as well as former High Representative of the Union for Foreign Affairs and Security Policy and Vice-President of the European Commission (HR/VP) Mogherini seeking to avoid 'any real kind of argument' in the FAC meetings (Maurer and Wright, 2020, p. 10). This development led one of their respondents to argue that 'quite a lot of foreign ministers have lost interest in [the FAC]' (ibid., p. 10). The gradual weakening of the FAC vis-à-vis the EUCO has also had implications for the CFSP CWGs. For example, the role of Coreper II, which sets the agenda for the EUCO, has been strengthened relative to the PSC, partly because the PSC does not prepare EUCO conclusions, and partly because the foreign policy files that are discussed are increasingly cross-cutting in nature, such as the migration crisis. This has led Coreper II to become 'much more interested in external policy', increasing the tensions between the two groups (ibid., p. 10). A likely consequence of the increase in cross-cutting foreign policy issues discussed at the EUCO would be that the lower-ranking CFSP CWGs have also been strengthened in relation to the PSC, as they increasingly prepare issues directly for the Coreper ambassadors. Although this development was not directly confirmed through the interviews, the view that the CWGs have a significant role to play in relation to the PSC in the policy-making process was emphasized.

5 As Coreper I is not involved in any of the files that the CFSP working groups deal with, 'Coreper' and 'Coreper II' will be used interchangeably in this book. 
For example, one representative to COEST explained the relation between COEST and the PSC in the following way:

From my point of view as a COEST delegate, I actually think that the PSC mostly fulfils the function of conveying our formal positions. Quite a lot of the discussions in the PSC are really not that operational, at least not when it comes to relations with third countries ... When my questions come up [in the PSC], it is often the case that there will be a full tour de table where all member states in three minutes summarize their positions. But when it comes to negotiating at the level of actually trying to solve problems beyond our formal positions, I think that happens more often in COEST, because the PSC does not have time for that - they have a far too broad mandate. (COEST 3)

\section{UNDERSTANDING THE PMG AND COEST}

Whereas the previous section situated the CWGs in the CFSP decision-making hierarchy, this section demonstrates how and why the CWGs differ among themselves as well as in relation to the higher-ranking CFSP committees, such as the PSC. Two CWGs have been selected as examples: the PMG and COEST. These groups are two of the most active CFSP CWGs in terms of the number of meetings held throughout the year (Chelotti, 2014a), and represent the two main types of CWGs: geographic and thematic. Therefore, they should be regarded as representative cases for the CFSP CWGs. Before comparing the PMG and PSC as well as the PMG and COEST, these two CWGs are described in further detail below.

COEST is formally responsible for preparing the EU's positions on relations to countries in Eastern Europe (Armenia, Azerbaijan, Belarus, Moldova, Georgia, Russia and Ukraine) as well as Central Asia (Kazakhstan, Kyrgyzstan, Tajikistan, Turkmenistan and Uzbekistan). As with research on other CFSP CWGs, few studies have specifically studied the inner workings of either the PMG or COEST. For COEST, one rare exception is a dissertation by Schmidt-Felzmann (2011), who found that the group is the most important platform for developing EU's position on Russia, as it is rare that the PSC or the Working Party of Foreign Relations Counsellors (RELEX) ${ }^{6}$ deal with Russia. Rather, policies regarding relations to Russia are directly sent to Coreper when COEST cannot form a consensus. However, it should be noted that the interviews for Schmidt-Felzmann's dissertation were conducted in 2007, so the impact of Russia's annexation of Crimea in 2014 was not included in the analysis. In contrast, recent studies have found that RELEX plays an important part in renewal of the sanctions regime against Russia, as it has been

6 RELEX is the main preparatory body for decisions related to restrictive measures (sanctions) against individuals and third countries. 
directly delegated this responsibility by the EUCO, bypassing the FAC as well as COEST (Portela et al., 2020; Szép, 2020). This arrangement is seemingly a conscious decision, as state leaders have been wary of a substantive debate that could revive the traditional cleavages that existed among EU member states before 2014. One respondent even argued that 'it is good that there is no discussion in COEST, because thanks to that there is a consensus' (Portela et al., 2020, p. 7). However, this critique of COEST should probably not be seen as a result of the group being particularly inefficient. More likely, it is the existence of "relatively 'hard' national red lines" in regard to relations to third countries in general, and Eastern European countries in particular, that make consensus difficult to find among all 27 member states. ${ }^{7}$

As its name suggests, the PMG is responsible for preparing issues that fall in between the recommendations and advice given for military and civilian Common Security and Defence Policy (CSDP) operations, which is chiefly provided by the European Union Military Committee (EUMC) and Committee for Civilian Aspects of Crisis Management (CivCom), and the political guidance provided by the geographic CWGs. That is, the PMG primarily deals with horizontal defence issues, such as the Permanent Structured Cooperation (PESCO), military mobility, and the European Peace Facility (EPF) and identifying and defining the strategic objectives of CSDP operations.

\section{COMPARISON 1: PMG AND PSC}

To understand the characteristics of lower-level CWGs such as the PMG and COEST, this section compares a lower-level working group (the PMG) with a higher-level working group (the PSC). An analysis is made using the NCEU dataset, which includes cooperation and negotiation variables on EU CWGs. The statistically significant $(p<0.05)$ differences of the means between the two groups are presented in Table 5.1. A comparison of the mean values reveals several interesting differences between the two groups. The most obvious difference is perhaps the variable that measures how long respondents have represented their country in EU working groups and committees in Brussels. As revealed in Table 5.1 and Figure 5.2, the PSC representatives have an average experience of 4.63 years, and the PMG representatives have an average experience of 3.19 years.

The main reason for the difference in the average degree of experience between the PSC and the PMG is the degree of seniority that is expected of the representatives posted to the PSC. Although the proposed level of 


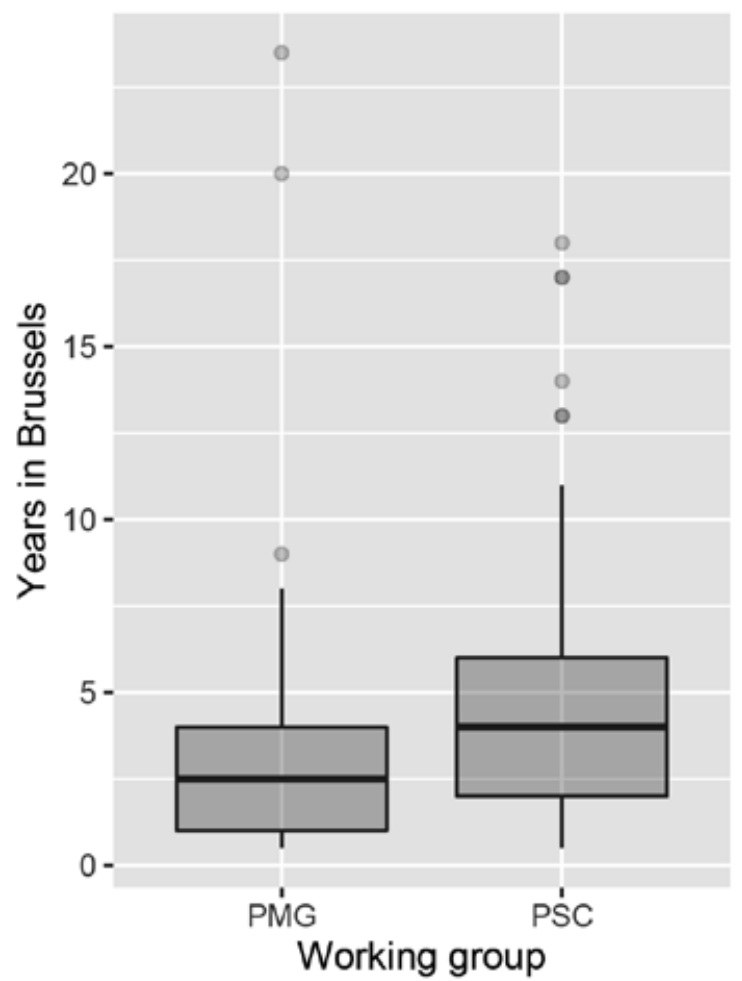

Figure 5.2 Average number of years representing repondents' member states in EU working groups and committees

seniority of the PSC ambassadors was extensively debated between member states during the development of the committee in 1999, the average age and seniority of the ambassadors has since increased (Howorth, 2011, p. 96). The difference in seniority between the PSC and PMG/COEST was also brought up as a significant difference between the groups throughout the interviews with the representatives from the lower-level CWGs (COEST 1, 3, 8; PMG 2 ). The difference in average age and experience was tied to the committees' positions in the decision-making hierarchy, which the respondents argued had the effect of making the PSC meetings 'formal' and 'not that relaxed' (PMG 2). In contrast, one respondent explained how there is 'less prestige involved' in the lower-ranking groups and that 'it's more acceptable to be insecure in your role in COEST [than in the PSC]' (COEST 3). 


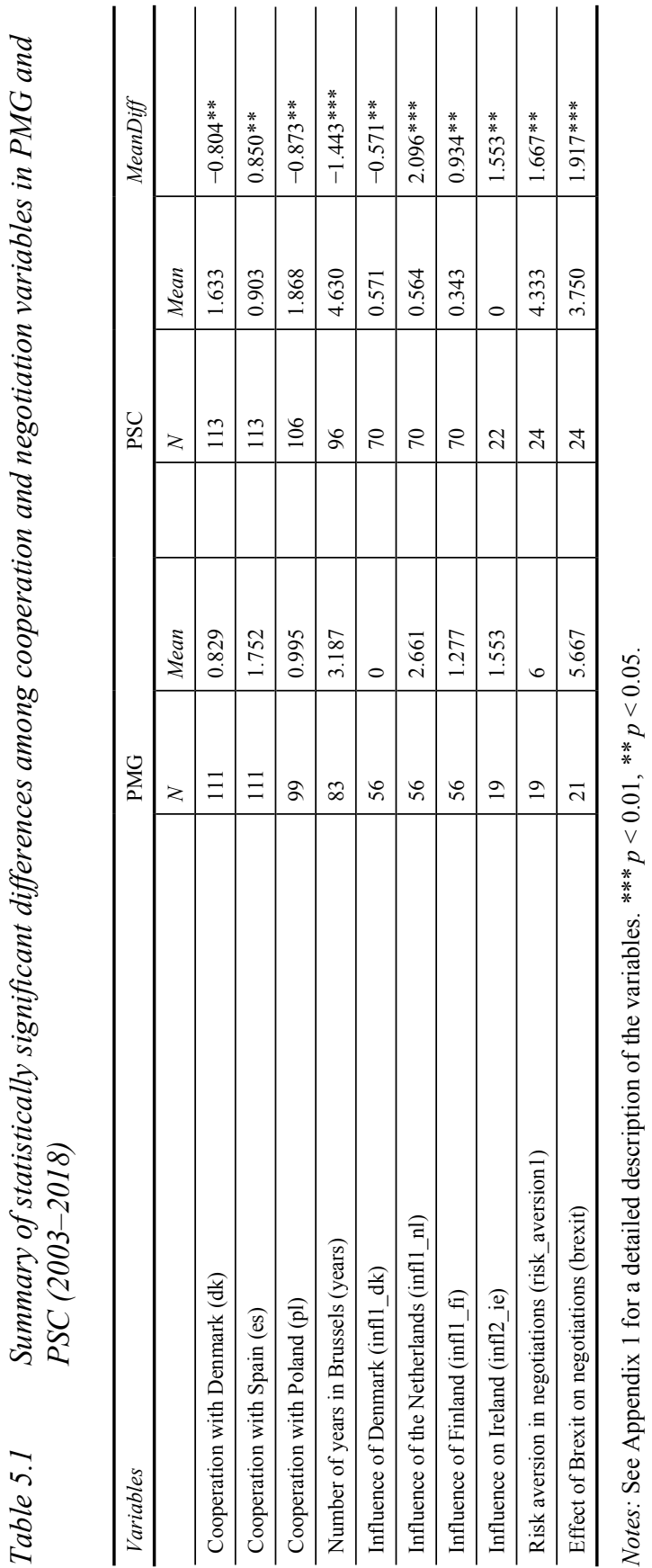


Another key difference between the PSC and PMG was the increased degree of risk aversion and perceived frequency of risky negotiations in the lower-ranking group. ${ }^{8}$ As Figure 5.3 shows, these differences indicate that the representatives in the PMG are more risk-averse than their PSC counterparts. This outcome can be explained by the fact that the lower-ranking groups perceive themselves to be where the real (and therefore riskier) negotiations take place, and that the PSC, in contrast, is simply a forum for reading instructions. For the purpose of this study, it does not matter whether this is a correct assessment, as it is the self-perception of the group members that shapes the identity and practices of the group.

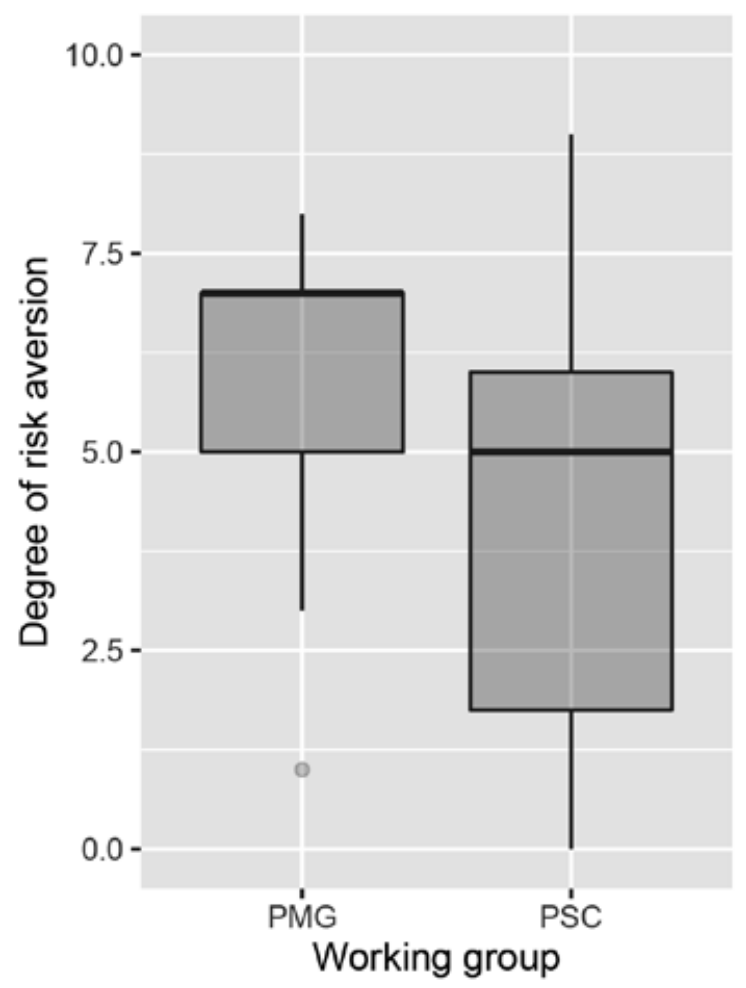

Figure 5.3 Risk aversion and perceived frequency of high-stakes negotiations in PMG and PSC

8 See Appendix 1 for a detailed description of these two variables. 
Choosing to take fewer risks may also simply be the effect of being on a lower level in the decision-making hierarchy. Compromises do not necessarily need to be found in the PMG, at least not to the same extent as in the PSC, as the lower-ranking $\mathrm{CWG}$ always has the option to send the issue to the higher-ranking committee. ${ }^{9}$ Therefore, the PMG representatives can afford to minimize risks in a way in which the PSC cannot.

Although some of the differences in the variables regarding the influence of a member state and cooperation patterns in the PMG and PSC can be explained by diverging policies (such as Denmark's opt-out from the CSDP making it a less common partner in the PMG), the remaining differences are likely best explained by differences among individuals. In other words, some representatives may simply be more (or less) active or influential than their national counterparts in the other committee. For example, simply as a result of having been in a committee for many years could give a representative greater weight and authority in the discussions, and therefore give this representative relatively greater influence in comparison to their counterpart in the other committee.

A difference between the groups that is somewhat easier to explain is the perceived effect of Brexit on negotiation patterns (Figure 5.4). The United Kingdom (UK), which has long been a sceptic of increasing the EU's joint defence capabilities, as doing so would risk duplicating NATO, would likely have had a larger influence on the discussions in the PMG than in the PSC, given the fact that the PMG only prepares CSDP issues and the PSC is responsible for preparing the whole CFSP agenda. This does not mean the UK did not have a significant impact on the discussions in the PSC, but simply that its opinion would have relatively greater weight in the PMG than in the PSC, as it would be more likely to oppose the proposals being discussed in the PMG. As a result, the effect of the UK leaving the EU will likely have a larger impact on cooperation patterns in the PMG than in the PSC. ${ }^{10}$ This sentiment was also confirmed in an interview with one of the representatives to the PMG:

PMG is one of the groups where you can see very clear traces of the fact that we no longer have a big player in the room. And we're still waiting to see how that will play out - how it will create a new dynamic in the group, new alliances, positions and so on. I think we're still in the middle of that process. (PMG 1)

9 For example, one of the COEST representatives argued that simply because they have the option to escalate an issue, they are less likely than the PSC ambassadors to be 'locked in a room and told they can't leave' (COEST 6).

10 For an analysis of how cooperation patterns in the Council have been affected by Brexit, see Johansson (2021). 


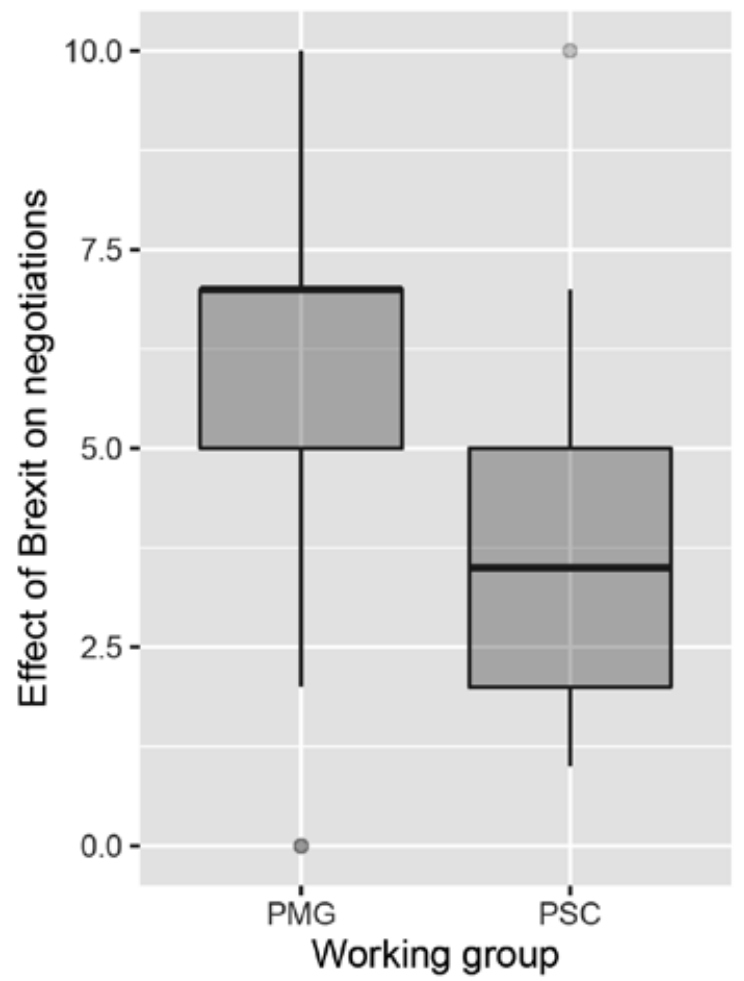

Figure 5.4 The impact of Brexit on negotiation patterns in the PMG and the PSC

In sum, although no significant difference exists between the majority of the variables regarding negotiation and cooperation patterns in the PMG and PSC, the ones that were significantly different between the two groups paint an interesting picture of how the representatives perceive themselves and their work. The representatives in the PMG seem to view their work as involving great risk, while at the same time being less prone to accepting compromises on high-stakes negotiations. Although these two perceptions are likely closely linked, they may also be the effect of the representatives in lower-ranking groups on average having less experience in EU negotiations. It is reasonable to expect that the more experience one gains from participating in negotiations, the less worried one might be about the effects of a non-favoured outcome, especially if such outcomes rarely lead to significantly adverse effects for the member state. 


\section{COMPARISON 2: PMG AND COEST}

The self-perception of frequently dealing with more sensitive negotiations is also reflected in the group identities that have developed in both the PMG and COEST. These group identities impact upon the expectations that the representatives have in regard to each other, which create and sustain the group's practices. To better gauge this effect and identify the particular practices of the PMG and COEST, this section outlines and discusses the currently existing norms and practices within the two groups, how these norms and practices are learned, the main characteristics of the group identities in the PMG and COEST, and how macro-level contestation affects the two groups as well as how this contestation is managed.

Although communities of practice should not solely be reduced to the formal groups of an institutional framework such as the CFSP (see Chapter 3), the interviewees made it clear that two communities of practice have gradually developed in the PMG and COEST. Both groups have several unwritten rules and norms regarding how consensus should be sought among their members, and how contestation among member states should be handled. In addition, there is a shared conception of what competence looks like; that is, the definition of what makes a good representative. Throughout the interviews, six attributes were mentioned as important characteristics of a good representative (see also Table 5.2):

1. Efficiency.

2. Perceptiveness (by formulating your argument in a way that considers the opposing side's views).

3. Subject knowledge (what is going on in the region, or theme that the working group is responsible for, as well as the other member states' positions).

4. Language skills (primarily in English).

5. Charismatic impersonality (presenting your member states' positions as if you truly believe in them, while at the same time avoiding being perceived as simply presenting your own opinions).

6. A strong mandate from one's capital.

This list of attributes essentially deals with the process of arguing a position in a meeting. The representatives to the PMG and COEST seem to primarily define each other's competence on the basis of their performance in their formal meetings. In other words, the 'backstage' of the negotiation process (such as corridor meetings) seems to be a less important stage for performing the group's definition of competence. 


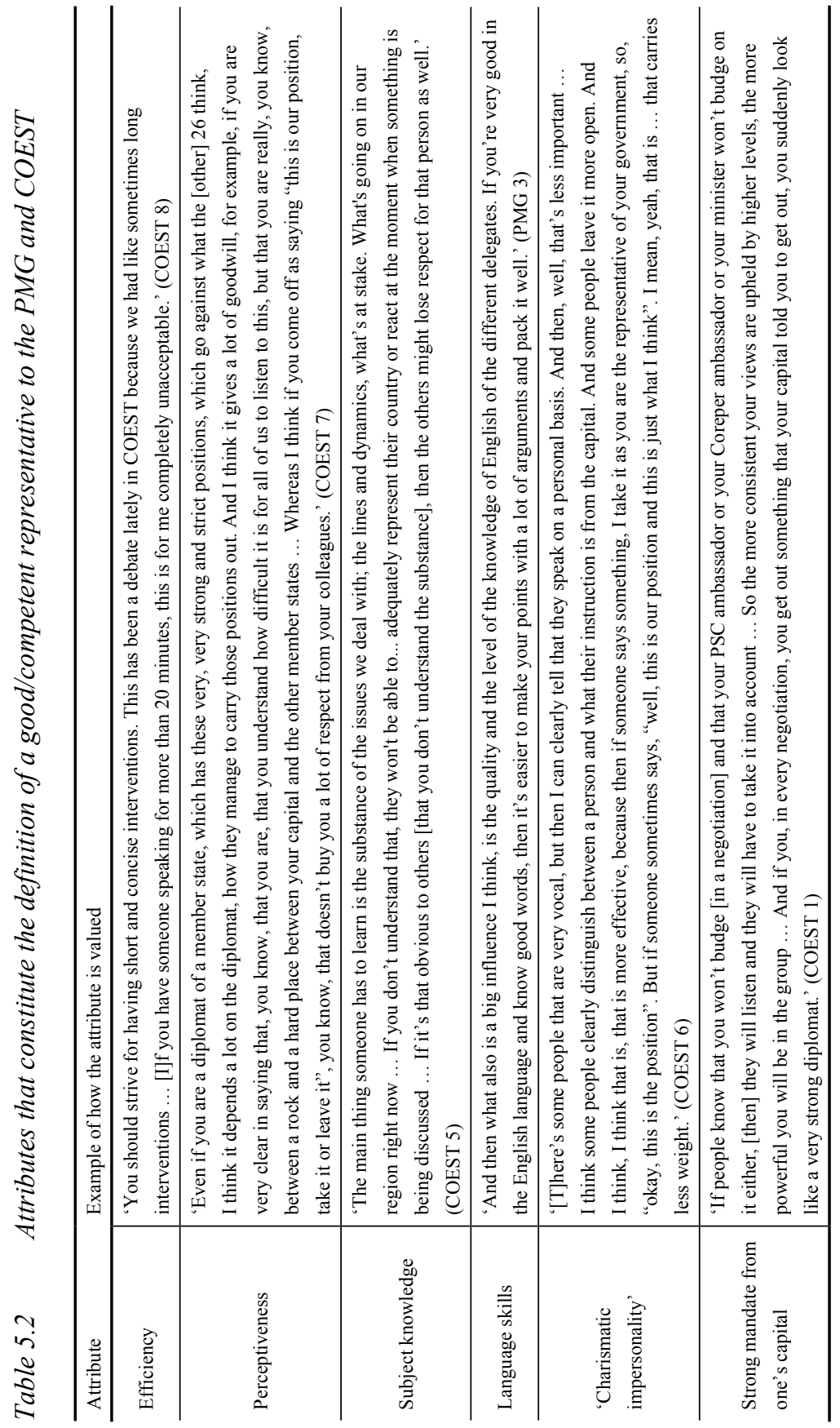




\section{Procedural Norms in the PMG and COEST}

In addition to the definition of a good representative, a number of procedural norms were also shared between the two groups. When asked about what the main unwritten rules are that structure the workings of the group, the respondents repeatedly mentioned that representatives are expected to act politely and respect each other (COEST 2, 3, 5, 8; PMG 2, 3), avoid personal attacks (COEST 1, 5, 8; PMG 5), avoid interrupting each other (PMG 2, 5), keep to the established order of speakers (PMG 2, 5), avoid repeating what they or someone else has already said ${ }^{11}$ (COEST 1, 5, 8), avoid backing something that no one has refuted or taken a position against (COEST 3,8), and give early signals to the chair of the group if they have a significant problem with a certain proposal (COEST 8; PMG 2). In essence, the groups seem to place a high value on acting efficiently and cordially, as those two attributes are seemingly the most important to uphold in order to find consensus. One of the respondents argued that none of the procedural norms are essential, in the sense that their work would collapse if that specific norm was not upheld, but that it is rather the combined existence of all of the aforementioned unwritten rules that enables consensus:

Some of them are quite minor rules, as long as they are being respected, but once they are ... If somebody doesn't respect them, not intentionally even, but just because they don't know them, it gives a weird vibe ... And none of them by themselves is at all problematic, but if people end up not respecting them, it, it creates a very difficult working atmosphere. (COEST 1$)$

An additional group norm that was brought up by two respondents was the notion that member states should 'know their place'. Smaller member states are expected to not argue as loudly as larger ones, and, therefore, 'not all member states are equal' (COEST 5). This expectation was described in the following way by one of the representatives to COEST:

If [you represent] a small country that may not have such tough positions on these issues, then I expect that country to manage its political capital. And it's often a problem that a new delegate comes in - a new ambitious delegate who has not really understood that your role in this group is probably to ... maybe contribute to consensus - it can be a very important role - but it can also be to signal when something is very important to you. We do not have time to listen to what you think about these positions, because we know that you will approve the final group

11 While at the same time being expected to back up the member states that you support, 'so you're expected to somehow creatively restate points that have to be made before, which is a challenge in itself' (COEST 1). 
consensus anyway. It's something that I think is ... [it's] not something that anyone really wants to say right to the face of an ambitious delegate from a small country ... So the expectations are very different depending on who you represent. (COEST 3)

\section{How Norms and Practices are Learned}

Beyond the similarities of the existing procedural norms in the two groups, the PMG and COEST also resemble each other in terms of how these norms are learned. When asked how they came to learn what is expected of them in their respective group, the respondents answered that it is very much a process of learning by doing (COEST 1, 5, 8; PMG 1, 3, 5). For example, one representative made the following observation: 'I saw other people act ... I knew my predecessor and we had like, two, three phone calls in advance and we saw each other also in Brussels. So, I was briefed. But most of the things you learn on the site' (COEST 8). For COEST, a document also exists that details some of the procedural norms of the group:

It's like the working methods. So how often we meet, the times we meet, how we conduct our discussions. Like for example, that our meetings, like the intervention should be limited in time, that we will ... it's more like practical arrangements rather than substantive. (COEST 5)

This document was sent to the representative by the chair of COEST shortly after she joined the group.

Although the learning process is quite inarticulate, the representatives did not feel that there were any significant repercussions from the group if and when they broke an informal rule that they had not yet learned: 'I think ... I think people note, but it's not something that is broadly discussed. There was this one person who joked with me, but like there's no, no broader discussion' (COEST 6). Instead, the unwritten rules of the group were learned through trial and error, seeing what works and what does not work (COEST 1). This sentiment was shared by the PMG representatives. When asked whether there were any consequences for breaking the norm of avoiding surprises, a PMG delegate made the following observation: '[T] here is like no punishment. It's rather the case that perhaps you're not perceived to be facilitating the conditions [for consensus]' (PMG 1). Another PMG delegate argued that the transition to virtual meetings had also made this learning process more difficult:

One thing, and that's why I liked those physical meetings a lot, and you can't really do that in VTC, is look at body language of the other people around the table. You have 27 colleagues around the table. If one person starts with the monologue, and you see, physically, five or ten colleagues who are tuning out and looking on their phone, for instance, then you know that that intervention might not be that successful. (PMG 3) 


\section{The Sources of Group Identities}

The groups' norms and practices were also quite clearly tied to the shared identities in the groups; in other words, the perception of what defines the PMG or COEST in relation to other CWGs. For example, representatives to both the PMG and COEST explained how their groups were seen as quite important in the CFSP decision-making process. One representative argued that COEST had relatively 'more weight' than some of the other regional working groups (COEST 6), and another COEST delegate argued that 'there are a lot of very intense bilateral issues which gives COEST delegates somewhat of an air of importance when it comes to their self-image. At least some of them, I'm sure' (COEST 1). For the PMG, this 'relative weight' was exemplified by the fact that the PMG delegates often act as substitutes in PSC meetings:

[F]rom my point of view, the PMG is seen as quite a heavy working group - an important player in the council working group structure ... there are also several in the group who quite regularly join the PSC as replacements for their ambassadors, when he or she is not available, [which is] a recognition, in some way, for the competence that exists in the group. (PMG 1)

At the same time, the relative importance of the group was also linked to inefficiency; as a result of discussing sensitive issues, representatives to both groups expressed how that could sometimes lead to stalemates in the negotiations. For example, when asked what defines the PMG, one representative made the following observation: 'I think that we are quite often known for not solving the issues and then going up to the higher levels when it comes to, to some more important issues like council conclusions' (PMG 2). When the same representative was asked to explain why the group cannot agree, the representative answered: 'Because those are ... Defence is a very ... defence is a very sensitive issue, of course' (PMG 2). Similarly, when comparing COEST to other working groups, one representative argued the following:

COEST seems to be one of the more rigid ones. The positions, I'm sure you know the vague positions and I won't get into them at all, but they are quite fixed for a lot of the member states. There's generally much less wiggle room than in some other groups, where the interests might shift more notably from one side to another. (COEST 1)

Another COEST representative argued that the group's identity is largely marked by the efforts that were made to ensure a joint EU response toward Russia's annexation of Crimea in 2014:

I don't have the exact figure, but COEST met more than 200 times in 2014 ... It demanded a lot from the COEST chairman ... so he prepared a paper on 'this is how 
we behave', 'this is how we act' - basically procedural rules at the COEST level to make the work more effective, to minimize the burden on the delegates. And also to enable the group to take decisions. I think that this legacy remains, and it contributes to an identity where we in COEST feel that we don't have time to spend a whole day on information points and to sit and talk about the situation somewhere in Africa. Instead, in order to engage COEST ... we need to have something to negotiate. The EU delegations can deal with the information exchange, the analysis. We are here to negotiate. I think that's the identity. In practice, I think we've gone from that to being more like any other working group. I don't think we're really as decision-focused as we were when I started in COEST. But the identity lives on, that COEST is an operative group. (COEST 3)

In other words, the perception of being an important player in the CFSP decision-making process is not necessarily related to the working group's ability to reach consensus, but rather to what degree they discuss and negotiate issues that are seen as salient by the member states. In this sense, the group's identities should also be understood as quite closely interlinked with the degree of cohesion and/or contestation that exists between member states.

\section{Managing Macro-Level Contestation}

The PMG and COEST differ in regard to how they have been affected by contestation between member states. For COEST, the main impact of member state contestation has been in regard to the EU's horizontal foreign policy or issues of fundamental values. As one representative argued: 'When it comes to gender identity, new rights ... Yeah, even gender quality, all those topics have become more and more difficult to discuss' (COEST 8). Specifically, Hungary and Poland were mentioned as the main transgressors:

[W] hat has become more challenging, I would say, is that the countries that I mentioned before [Hungary and Poland] have started to challenge parts of the EU's horizontal foreign policy - not least in regard to gender equality, gender issues, Women, Peace and Security and SRHR [sexual and reproductive health and rights]. (COEST 3)

The effect of this contestation is that it has become more difficult for the member states to reach consensus in the group (COEST 5).

In contrast, the PMG representatives argued that they had been spared any spillover from the member state contestation on horizontal issues, largely due to the fact that the chair of the PMG has been able to insulate the group from those types of discussions (PMG 1, 2, 5):

I think the group isn't really that affected by the issues that are problematic in other contexts. Whether that's gender issues or migration - things that some other groups tend to get a bit stuck in. My experience is that in PMG - partly it has to do with 
diverging issues, but even when we do end up discussing those issues - my experience is that PMG often succeeds, I don't know, I guess for the sake of the common good, to keep going. (PMG 1)

However, despite the absence of contestation on horizontal issues, the PMG is still affected by contestation between member states due to the fact that the issues that the PMG are responsible for have become increasingly polarized. For example, one representative argued that developments over the past years have brought to a head the contestation regarding the EU's role in security and defence: ' $[\mathrm{N}]$ ow it is a little more high stakes, and maybe more ... there's more diverging visions about which path we should choose' (PMG 1). Another representative argued that, 'I would say that [now] it is more difficult, at least as a starting point, to reach consensus' (PMG 5).

However, although both the PMG and COEST deal with contentious issues, this has not led to a deterioration of the atmosphere in either of the two groups. For example, one of the COEST representatives argued that 'even though we have this dichotomy, or this elephant in the room, dividing us into pro-Russian and to anti-Russian, there's still good spirits in the group' (COEST 5). Similarly, another representative explained that 'people say that now there's quite a good atmosphere in COEST. That even though some of the topics are very difficult, personal relationships are quite good' (COEST 6). The same was true for the PMG. When asked if they had seen any adverse effects on personal relationships within the group due to contestation between member states, a PMG delegate made the following observation:

No, I haven't. To be honest, I haven't. I have seen people from both camps get along with each other very much. So that's not the case. If anything would influence the way people think about each other, it's personalities. And it's the way that you sometimes push for something, or get personal in your arguments, or are not polite anymore, or those types of things. And that, I think, has to do with personality and not with strategy or with national positions. (PMG 3)

In other words, while both the PMG and COEST are exposed to macro-level contestation, albeit on different issues, both groups have seemingly upheld a strong sense of cohesion within the group. In fact, and somewhat paradoxically, the atmosphere within the two groups almost seems to have improved in line with decreasing cohesion among the member states. If anything, this indicates that macro-level contestation does not determine how or to what degree a community of practice - such as the PMG and COEST - is able to create and maintain its practices. 


\section{CONCLUSION}

Despite increasing contestation between member states, the members of these two communities of practice still view their practices to be of key importance for doing their job; that is, finding consensus on as many files as possible. When consensus becomes harder to find due to diverging member state positions, these practices arguably only grow in importance. There is thus an argument to be made that macro-level contestation can, to some degree, serve to reinforce practices of the group. As contestation increases, so does the group members' reflexivity regarding the constitutive elements of a good and functional work environment, as they need to figure out what works (and what does not) in the process of forging consensus. In other words, it should not be seen as a coincidence that the representatives mention certain moments where consensus was harder to be found (such as the period following Russia's annexation of Crimea) as critical junctures for the development of new procedural rules. These rules eventually become self-evident practices that are learned by doing. They are not upheld through arguments or attempts at persuasion, but rather by non-reflexive reactions to rule-breaking behaviour. However, this does not mean that these practices cannot be reflected upon (see Chapter 3). As has been shown throughout this chapter, the representatives to both the PMG and COEST are well aware of the constitutive rules of the practices that structure their work, including the consequences of breaking these rules.

As stated in the introduction, this chapter had two main aims: to compare the CFSP CWGs, as well as to compare the CFSP CWGs with the higher-ranking committees in the CFSP decision-making hierarchy. Through a comparison of the PMG and PSC, the main difference between a low-ranking group and a high-ranking group was found to be that members of working groups such as the PMG are more junior, while at the same time perceiving themselves as dealing with more sensitive issues than their higher-ranking counterparts. It is not unlikely that these two outcomes are intertwined. The comparison between the PMG and the PSC thus highlights the potential effect of hierarchy on a group's practices. A larger comparative study of higher-ranking and lower-ranking working groups would need to be conducted to understand to what degree this is an empirically general phenomenon among EU CWGs.

The comparison between the PMG and COEST revealed a difference regarding the impact of contestation of horizontal issues. Here, the chairs of the respective CWGs seemingly play a large role, primarily in the case of PMG, by insulating the group from such discussions. In most other aspects, the two CWGs were remarkably similar. They had more or less the same procedural rules, and their group identities were both clearly linked to a sense of importance and status in relation to other working groups on the same formal 
level in the decision-making hierarchy. To understand why this is the case, however, we need to compare a larger sample of lower-ranking CWGs. For example, the similarity between these two groups could be the result of how often they meet, the saliency of the issues they discuss, the characteristics of the representatives, or simply coincidence. Identifying additional conditions that drive variations in practices and norms in both similarly and differently ranked CWGs should thus be a subject for future research. 